\title{
Patient Medication Instruction and Provider Interactions: Effects on Knowledge and Attitudes
}

\author{
Pamela L. De Tullio, PharmD \\ Stephen A. Eraker, MD \\ Christopher Jepson, PhD \\ Marshall H. Becker, PhD, MPH \\ Elaine Fujimoto, PharmD \\ Cindy L. Diaz, PharmD \\ Robert B. Loveland, PharmD \\ Victor J. Strecher, PhD, MPH
}

This prospective study examines whether a patient medication instruction sheet (PMI) given to clinic patients by their health care provider affects knowledge and/or attitudes with thiazide diuretic use as part of an antihypertensive regimen.

Adult male patients $(N=285)$ in a general medicine clinic were assigned to groups receiving the Amcrican Medical Association PMI describing their diurctic. Patients getting the PMI obtained it either directly from their provider or at the pharmacy dispensing window. All patients were surveyed by phone 1 week following the clinic visit with regard to the PMI, knowledge of medication use, and attitudes toward drug use.

Results indicate that a provider-dispensed PMI results in higher levels of drug knowledge and greater patient satisfaction with their knowledge than a pharmacy-dispensed PMI. In addition, the PMIs educational value may be lessened by an incomplete verbal consult. This study demonstrates that the AMA PMI is an effective educational tool when distributed by a provider and can promote better understanding and use of prescribed medications.

P. L. De Tullio is from the Ann Arbor VA Medical Center and University of Michigan College of Pharmacy, Ann Arbor, Michigan. S. A. Eraker is from the Salt Lake City VA Medical Center, Utah. C. Jepson is from Vanderbilt University, Nashville, Tennessee. M. H. Becker is from the University of Michigan School of Public Health. E. Fujimoto is from Kaiser Hospital, Los Angeles. California. C. L. Diaz and R. B. Loveland are from University of Michigan College of Pharmacy. Ann Arbor, Michigan. V. Strecher is from the University of North Carolina School of Public Health. Chapel Hill, North Carolina.

This work was supported by grant support to Dr. Eraker from the Veterans Administration.

Address reprint requests to Pamela L. De Tullio, Veterans Administration Medical Center, Department of Pharmacy, 2215 Fuller Road, Ann Arbor, Michigan 48105. 


\section{INTRODUCTION}

Most physicians. pharmacists, and other health care professionals agree that patients should be educatcd about their drug therapy and encouraged to participate in medical decisions, but much controversy exists concerning the best method(s) for accomplishing this goal. During the 1970s, the patient package insert (PPI) was widely promoted as a way to increase patient knowledge and to encourage proper use of medications. Some suggested that the PPI might enhance medication compliance, decrease adverse side effects, and improve patient-provider communications.' Others were skeptical that PPls could achieve these objectives, arguing that these messages probably would not be read or, if read, that they would promote inappropriate self-medication, foster prescription drug exchange among patients, produce suggestion-induced side effects in "susceptible" individuals, and alarm patients to the point of their disregarding needed drug therapy. 1.2

Research in this area has now demonstrated that: patients desire written information about their medications ${ }^{3.4}$; the majority of patients read the information they receive ${ }^{5-7}$; written information can improve patients' knowledge about their therapy, ${ }^{2,49}$ and the best effects are achieved when both verbal and written information are presented ${ }^{2.8}$; the amount of physician-patient contact time is not significantly affected by giving the patient a PPI ${ }^{6}$; PPIs improve compliance in short-course antibiotic therapy, ${ }^{2.8}$ but results are mixed with regard to drug regimens for chronic conditions. ${ }^{2}$

Although these investigations produced some promising results, the FDA rescinded a proposed program requiring PPI distribution for a select group of drugs in 1982 . This decision was based on evaluations of the PPI program (including those sponsored by the FDA) that suggested that PPIs would be expensive and that the cost would not be justified since PPIs would not significantly alter patients' established drug use patterns, influence their decisions about whether to take medication, increase compliance, or encourage the reporting of side effects. ${ }^{10}$ However, other organizations continued to provide written drug information in response to consumer demand.

One approach that has generated considerable interest among consumers and health professionals is the Patient Medication Instruction (PMI) program of the American Medical Association (AMA). Advocates of the program assert that written information provided at the time the drug is prescribed (rather than at the pharmacy dispensing window) should strengthen the physician-patient relationship, reduce improper drug use, decrease the incidence of preventable and serious adverse drug reactions, and improve patient compliance. Unlike the FDA PPI program, the cost is nominal $(\$ 0.50$ to physician per pad of $100 \mathrm{PMI}$ drug sheets), and the time/effort required to use the PMI during a visit is minimal. ${ }^{1}$

Because the PMI program is currently being promoted as superior to the packagebased information sheets, we have gathered data relevant to the following issues:

1. Does the environment in which written information is dispensed matter (i.e., will whether the PMI is given to the patient by the provider or at the pharmacy dispensing window affect patient knowledge, attitudes, and use of a chronic medication)?

2. Does type of provider influence the effects of the PMI?

3. Does a verbal consult enhance the effects of the PMI (and if so, which ones)? 


\section{METHOD}

\section{Subjects}

The study population consisted of 285 adult male hypertensive patients who attended the outpatient general medicine clinics at a Veterans Administration Medical Center. Patients ranged in age from 35-79 years, with a mean age of 60.6 years. Any patient receiving a new or refill prescription for a thiazide diuretic as part of his antihypertensive regimen was included. Informed consent forms were placed in all patients' charts in the general medicine clinics at the beginning of each day. When a provider encountered a patient receiving a thiazide diuretic, that patient was asked to participate in the study by reading and signing the consent form.

\section{Study Design}

Patients were assigned to one of three experimental groups or the control group over a 4-month period. Groups were run consecutively by month.

By the end of the first month, 93 patients had met the study criteria and were assigned to the control group. These patients received no special information about their diuretic during the course of the study. During the second study month, 54 patients were assigned to group I. Patients in this group received written drug information at the pharmacy dispensing window in a bag along with their medication (pharmacy/PMI). The written information used in this study was the Patient Medication Information sheet on thiazide diuretics published by the AMA. It describes in layman's terms uses and actions of the medication, proper administration, and precautions. It also describes medication side effects, specifying those that should be reported to a doctor and those that may not require immediate attention.

Seventy-nine patients met study criteria during the third study month and were assigned to group II. Group II patients received their PMI from a provider (provider/PMI). Six staff physicians, three physician assistants, and two clinical pharmacists served as providers in the study. Finally, during the fourth month of the study, 59 patients were assigned to group III. Patients in this group received both the PMI and a verbal consult from their provider (PMI/consult); the latter was a standardized consult based on information that is commonly discussed with patients about their diuretic during typical office visits (APPENDIX).

A six-page telephone interview (lasting about 20 minutes) was developed and pretested to assess the effects of the PMI and consult. The items in the interview focused on four main topics.

\section{Attitudes toward Use of the PMI}

These questions were designed to evaluate both patient satisfaction with various aspects of the PMI and the extent to which patients were making use of it. For example, patients were asked if they had read the PMI, had gone back to it at any time, felt they knew more since receiving it, wanted more information. 


\section{Perceived Drug Knowledge}

These questions measured how much the patients thought they knew about the diuretic and how to take it. For example, patients were asked to rate, on a five-point scale, how satisfied they were with their knowledge of various issues relating to their diuretic, such as directions for use, possible side effects, what to do about side effects, and what foods to eat or avoid.

\section{Objective Knowledge of Diuretic Therapy and Hypertension}

These questions were designed to assess the actual levels of patient knowledge regarding the information presented in the PMI. For example, patients were asked to respond to open-ended questions concerning directions for use, side effects, foods to eat and avoid, and problems caused by untreated hypertension.

\section{Experience with and Attitudes toward Side Effects}

This topic included such questions as whether the patient had ever experienced side effects, what side effects he had experienced, and how concerned he was about side effects.

Each patient was interviewed approximately 1 week after his clinic visit. Patients who had received a PMI were explicitly discouraged from retrieving it for use during the interview.

\section{Scoring}

Although most of the interview items were closed ended, eight questions obtained open-ended responses. One of these items concerned which side effects the patient might have had experienced; the others assessed the patient's knowledge of PMI information. Patients' responses were coded according to one of two methods. For those questions to which multiple correct answers were expected, patients received a score corresponding to the number of correct responses they gave to each question. For the other items, patients" answers were simply scored as either correct or incorrect ("don't know" answers were coded as incorrect). Some patients responded with answers that could be correct but were not covered in the PMI; these responses were excluded from the analyses.

For each patient, an overall knowledge score was created by dividing the number of correct answers by the total number of questions asked. The numerator included all knowledge questions for which at least one correct answer was given by the patient.

\section{Analyses}

The statistical test employed in our analyses was the Goodman-Kruskal $\gamma$, a nonparametric bivariate measure of linear correlation. This statistic ranges from -1 (per- 
fect negative correlation) through 0 (complete independence) to +1 (perfect positive correlation). In this article, the sign of correlation is given as positive when the correlation is in the expected direction and negative when opposite to the direction hypothesized.

\section{RESULTS}

\section{Attitudes toward and Use of the PMI}

Findings concerning PMI utilization and perceived need for more information are summarized in Table 1.

By combining the reports of patients in groups I (pharmacy/PMI) and II (provider/PMI), responses reflect the effect of the PMI alone: $81.9 \%$ of these patients reported having read the PMI, and $72.3 \%$ felt that they knew more after receiving it. In addition, only $20.9 \%$ felt that they needed more information about their diuretic, as opposed to $38.2 \%$ of patients who did not receive a PMI, a significant difference $(\gamma=0.40 ; p<0.01)$. Further analysis revealed that $92 \%$ of patients having received a PMI had it 1 to 2 weeks later and that the majority of patients were satisfied with the informational content. These results may be somewhat better than those that would normally be obtained outside the study setting; since the patients knew they were participating in research, some may have felt a greater obligation to read the PMI. In practice, however, the same effect might be accomplished by having the provider ask the patient to read the PMI.

One significant difference was found among the three experimental groups. Group III (PMI/consult) patients were more likely to refer back to the PMI than were patients in groups I and II $(\gamma=0.45 ; p<0.01)$.

Table 1. Attitudes toward and Use of the PMI (by Study Group)

\begin{tabular}{|c|c|c|c|c|}
\hline \multirow[b]{2}{*}{ Question } & \multicolumn{4}{|c|}{ Percentages } \\
\hline & Control & Group I & Group II & Group III \\
\hline Have you read the PMI? & $N A^{a}$ & $\begin{array}{c}84.0 \\
(42 / 50)\end{array}$ & $\begin{array}{c}80.5 \\
(62 / 77)\end{array}$ & $\begin{array}{r}87.9 \\
(51 / 58)\end{array}$ \\
\hline $\begin{array}{l}\text { Have you gone back to the } \\
\text { PMI?? }\end{array}$ & NA & $\begin{array}{l}19.6 \\
(9 / 46)\end{array}$ & $\begin{array}{c}13.7 \\
(10 / 73)\end{array}$ & $\begin{array}{r}33.3 \\
(19 / 57)\end{array}$ \\
\hline $\begin{array}{l}\text { Do you think you know more } \\
\text { about your water pill } \\
\text { now than before you } \\
\text { received the PMI? }\end{array}$ & NA & $\begin{array}{c}80.4 \\
(37 / 46)\end{array}$ & $\begin{array}{c}67.1 \\
(49 / 73)\end{array}$ & $\begin{array}{c}72.7 \\
(40 / 55)\end{array}$ \\
\hline $\begin{array}{l}\text { Do you feel you need more } \\
\text { information about your } \\
\text { water pill? }\end{array}$ & $\begin{array}{c}38.2 \\
(21 / 55)\end{array}$ & $\begin{array}{c}22.6 \\
(12 / 53)\end{array}$ & $\begin{array}{c}19.7 \\
(15 / 76)\end{array}$ & $\begin{array}{c}20.3 \\
(12 / 59)\end{array}$ \\
\hline
\end{tabular}

"NA $=$ not applicable ${ }^{b} p<0.01$. 


\section{Satisfaction with Knowledge Acquisition}

Table 2 presents the data concerning patient satisfaction with perceived drug knowledge.

Patients in the experimental groups were significantly more satisfied than the control group with their overall perceived drug knowledge $(p<0.0001)$. However, within the experimental groups, differences are not large, nor are they very consistent. The main distinction scems to be that group I (pharmacy/PMI) patients were generally less satisfied than were patients who received their PMI from a provider (groups II and III).

Additional insights on the topic of perceived knowledge acquisition are provided by findings in Table 3 , which presents patients' responses to questions concerning how much people at the clinic told them about the same four items covered in Table 2. As anticipated, patients who were given a provider consult (group III) reported receiving more information at clinic than did patients in either group I or II. What is interesting is that this difference was also obtained for the two items about side effects, since information concerning side effects was not included in the standardized consult (APPENDIX) but rather was provided in the PMI. It would seem that, when a verbal consult is presented in conjunction with a PMI, the patient's perception of the scope of information given in the consult expands to assimilate information that was in fact learned by having read the PMI.

\section{Objective Knowledge Acquisition}

Results concerning patients' actual knowledge acquisition are summarized in Table 4.

Overall, patients in the experimental groups scored higher on objective knowledge than patients in the control group. The only exception involved responses to a question concerning what serious problems could be caused by untreated hypertension: on this

Table 2. Patient Satisfaction with Acquired Knowledge (by Study Group)

\begin{tabular}{llllllll}
\hline & \multicolumn{3}{c}{ Mean Satisfaction Ratings. } & & \multicolumn{2}{c}{ Correlations } \\
\cline { 2 - 4 } $\begin{array}{c}\text { Question } \\
\text { Description }\end{array}$ & Control & Group I & Group II & Group III & $\begin{array}{c}\text { Control versus } \\
\text { Groups I-III }\end{array}$ & $\begin{array}{c}\text { Group I versus } \\
\text { II versus III }\end{array}$ \\
\hline $\begin{array}{c}\text { Directions for } \\
\text { use }\end{array}$ & 4.161 & 4.585 & 4.734 & 4.707 & & $0.464^{\mathrm{d}}$ & 0.182 \\
$\begin{array}{c}\text { Possible side } \\
\text { effects }\end{array}$ & 2.957 & 4.132 & 4.317 & 4.276 & & $0.614^{\mathrm{d}}$ & 0.040 \\
$\begin{array}{c}\text { What to do about } \\
\text { side effects }\end{array}$ & 2.847 & 4.019 & 4.000 & 4.310 & & $0.555^{\mathrm{J}}$ & $0.149^{\mathrm{J}}$ \\
$\begin{array}{c}\text { Foods to cat and } \\
\text { avoid }\end{array}$ & 2.935 & 3.717 & 4.064 & 4.172 & & $0.489^{\mathrm{d}}$ & $0.190^{\mathrm{J}}$ \\
\hline
\end{tabular}

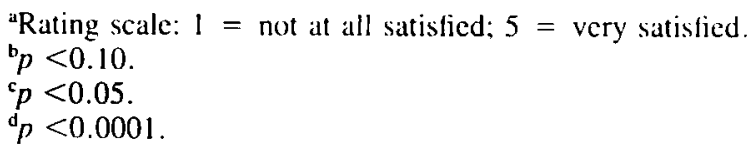


Table 3. Perceived Knowledge Acquisition (by Study Group)

\begin{tabular}{llcccc}
\hline \multirow{2}{*}{$\begin{array}{c}\text { Question } \\
\text { Description }\end{array}$} & Control & Group I & Group II & Group III & $\begin{array}{c}\text { Corrclations: } \\
\text { Groups III versus } \\
\text { Groups I and II }\end{array}$ \\
\cline { 2 - 5 } & 3.250 & 3.788 & 3.468 & 3.898 & $0.189^{\mathrm{h}}$ \\
\hline $\begin{array}{c}\text { Directions for } \\
\text { use }\end{array}$ & 1.978 & 2.434 & 2.167 & 2.793 & $0.276^{\mathrm{c}}$ \\
$\begin{array}{c}\text { Possible side } \\
\text { cffects }\end{array}$ & 2.099 & 2.154 & 1.922 & 2.842 & $0.404^{\mathrm{e}}$ \\
$\begin{array}{c}\text { What to do about } \\
\text { side cffects }\end{array}$ & 2.286 & 2.283 & 2.423 & 3.170 & $0.362^{\mathrm{d}}$ \\
$\begin{array}{c}\text { Foods to eat and } \\
\text { avoid }\end{array}$ & & & & & \\
\hline
\end{tabular}

"Rating scale: $I$ = "I was told nothing": 5 = "I was told a lot."

$\mathrm{b} p<0.01$.

c $p<0.01$.

$\mathrm{d}_{p}<0.001$.

${ }^{\circ} p<0.0001$

Table 4. Objective Knowledge Acquisition (by Study Group)

\begin{tabular}{|c|c|c|c|c|c|c|}
\hline \multirow[b]{2}{*}{$\begin{array}{l}\text { Question } \\
\text { Description }\end{array}$} & \multicolumn{4}{|c|}{ Knowledge Scores } & \multicolumn{2}{|c|}{ Corrclations } \\
\hline & Control & Group I & Group II & Group III & $\begin{array}{l}\text { Control versus } \\
\text { Groups I-III }\end{array}$ & $\begin{array}{l}\text { Group I versus } \\
\text { II versus III }\end{array}$ \\
\hline $\begin{array}{l}\text { What might happen if } \\
\text { medication is not } \\
\text { taken }\end{array}$ & 0.602 & 0.796 & 0.810 & 0.915 & $0.299^{f}$ & 0.065 \\
\hline $\begin{array}{l}\text { Food to eat while taking } \\
\text { diuretic }^{d}\end{array}$ & 0.447 & 0.519 & 0.893 & 0.825 & $0.320^{i}$ & $0.175^{d}$ \\
\hline $\begin{array}{l}\text { Serious problems caused } \\
\text { by untreated } \\
\text { hypertension }\end{array}$ & 1.398 & 1.463 & 1.769 & 1.424 & 0.149 & -0.057 \\
\hline $\begin{array}{l}\text { How long medication } \\
\text { must be taken }\end{array}$ & 59.1 & 66.7 & 82.3 & 72.9 & $0.349^{r}$ & 0.091 \\
\hline $\begin{array}{l}\text { Side effects to be } \\
\text { reported to } \mathrm{MD}^{\mathrm{h}}\end{array}$ & 15.7 & 37.5 & 61.1 & 29.5 & $0.643^{z}$ & -0.114 \\
\hline $\begin{array}{l}\text { Time of day to take last } \\
\operatorname{dose}^{b}\end{array}$ & 16.1 & 33.3 & 53.2 & 67.8 & $0.399 "$ & $0.421^{g}$ \\
\hline Short-term side effects ${ }^{b}$ & 3.3 & 14.9 & 27.8 & 16.4 & $0.770^{\mathrm{g}}$ & $0.006^{\mathrm{g}}$ \\
\hline Overall & 38.5 & 48.0 & 62.2 & 57.1 & $0.492^{g}$ & $0.145^{\mathrm{c}}$ \\
\hline
\end{tabular}

aFigures are mean number of correct responses per patient.

bFigures are percentage of patients answering question correctly.

'Figures are mean percentage of questions answered correctly per patient.

${ }^{4} p<0.10$.

$c p<0.05$.

$r_{p}<0.01$

${ }^{p} p<0.0001$. 
item, control patients performed about as well as patients in any of the experimental groups. A possible explanation for this unexpected finding is the introduction, within the last several years, of considerable information in the mass media informing the public of the dangers of uncontrolled hypertension (thus enabling the controls to achieve higher scores on this item).

Within the experimental groups, it might have been expected that group III patients (PMI/consult) would have scored higher than group I (pharmacy/PMI) or group II (provider/PMI) patients. However, this was not the case. Further analyses revealed that group II patients performed the best with group III intermediate and group I scoring lowest (the correlation for the overall score was significant at the 0.002 level). These findings may result from the fact that the questions asked during the interview dealt with information contained only in the PMI and not in the provider consult. Thus, it is possible that the consult may have had the effect of making the additional information in the PMI seem less important to that patient, since it was not reviewed by the provider.

\section{Experience with and Attitudes toward Side Effects}

Table 5 presents findings regarding side effects.

Although patients in groups I-III were significantly more likely than were control patients to report having experienced side effects and to report more side effects per patient on the average $(p<0.002)$, there was essentially no difference in rating of concern.

\section{Effects of Provider Type}

Separate analyses were performed on patients in groups II and III (i.e., patients receiving their PMI from a provider) to determine whether provider type (MD, PA.

Table 5. Experience of and Attitudes toward Side Effects (by Study Group)

\begin{tabular}{clcccc}
\hline \multirow{2}{*}{$\begin{array}{c}\text { Question } \\
\text { Description }\end{array}$} & Control & Group I & Group II & Group III & $\begin{array}{c}\text { Correlations: } \\
\text { Control versus } \\
\text { Groups I-III }\end{array}$ \\
\cline { 2 - 5 } & 14.3 & 29.6 & 28.1 & 32.2 & $0.437^{\mathrm{d}}$ \\
$\begin{array}{c}\text { Ever experienced any } \\
\text { side effects }\end{array}$ & 0.118 & 0.264 & 0.253 & 0.322 & $0.475^{\mathrm{d}}$ \\
$\begin{array}{c}\text { Number of correct } \\
\text { side effects }\end{array}$ & 3.086 & 3.407 & 3.115 & 3.254 & 0.055 \\
$\begin{array}{c}\text { Concern about side } \\
\text { effects }\end{array}$ & & & & & \\
\hline
\end{tabular}

"Figures are percentage of patients answering "Yes."

bFigures are mean number of correct side effects (defined as side effects listed in PMI) reported by patient.

'Figures are mean ratings of concern. Rating scale: $1=$ not concerned at all; $5=$ very concerned.

${ }^{\mathrm{d} p}<<0.002$. 
PharmD) had any effect on patients' responses. Virtually no significant differences were found, indicating that for the kind of limited patient-provider interactions used in this study, type of provider is not a very important factor.

\section{DISCUSSION}

Should providers be involved in educating patients regarding the benefits and risks of drug therapy or in the dispensing of PMIs? This investigation demonstrated that the AMA PMI can be an effective educational tool when distributed by a provider with or without a verbal consult. Although it has often been claimed that patients will not bother to read drug information, our study (and others ${ }^{5-7}$ ) found that the written information (PMI) given to patients was read in the majority $(>80 \%)$ of cases. Furthermore, we determined that over $90 \%$ of our patients still had the PMI in their possession 2 weeks after receiving it.

Results indicate that patients who get their PMI from a provider are more likely $(p<0.05)$ to continue to use it than are those patients who receive the PMI as a package insert in the bag with their medications at the pharmacy dispensing window. It may be that the personal attention given to these patients makes the PMI seem more important. A potentially confounding factor, however, may exist with regard to the content of the consult given to study patients. Group III (consult) patients referred back to the PMI more often, yet scored lower on objective knowledge questions that did group II (provider/PMI) patients. We speculate that in order for a consult to enhance the PMIs educational value, the provider must verbally communicate the PMI information with which he would like the patient to become familiar; patients seem to attach importance only to the verbally transmitted information, and it is only that information on the PMI that is reinforced (and, therefore, easier to retain). On the other hand, patients who receive a PMI from their provider without an accompanying consult may be more inclined to perceive all of the PMI information as important and will review the entire content more carefully (thus actually learning more than do patients in the "consult" group). Further study of the value of more complete consults is needed.

Results of our interview are consistent with previous research on PPIs, which found higher levels of knowledge of drug use and side effects among patients who received written information than among those who did not. ${ }^{4.5}$ Furthermore, our data show that patients' satisfaction with their diuretic knowledge was greatly enhanced when they obtained their PMI from a provider, especially with regard to information received on foods to eat or to avoid when using a diuretic. Objective knowledge acquisition was significantly improved in all areas (with the exception of the question concerning consequences of uncontrolled hypertension) when the PMIs were dispensed to patients by their providers.

Our findings support investigations indicating that patients prefer to receive drug information from physicians. ${ }^{5.12}$ It should be noted, however, that in this study, patient satisfaction with drug knowledge and objective acquisition were not significantly modified by the type of provider with whom the patient interacted.

Providing information about side effects may well increase patient reporting of those side effects but does not increase patient concern. These data suggest that listing side effects in the PMI should not adversely affect a patient's drug-taking behavior. The 
results indicate that a PMI can have a positive impact on patient education and may be effectively utilized by the patient's health care provider to promote better understanding and use of prescribed medications.

\section{APPENDIX}

\section{Standardized Consultation}

- (Name of drug) is a diuretic, also known as a "water pill."

- This medicine is used in the treatment of high blood pressure.

- Since this medicine may make you urinate more frequently, you should take your water pill in the morning (or if you are taking more than one dose, no later than $6 \mathrm{PM}$ in the evening).

- While you are taking this medicine. you should reduce the amount of salt that you use; you may use a salt substitute.

\section{References}

1. Institute of Medicine: Evaluating patient package inserts. Washington, National Academy of Sciences. 1979.

2. Morris LA. Halperin JA: Effects of written drug information on patient knowledge and compliance: A literature review. Am J Public Health 69:47-52. 1979.

3. Jouber P. Lasagna L: Patient package inserts. I: Nature, notions and needs. Clin Pharmacol Ther 18:507-513, 1975

4. Fleckenstein L. Jouber P: Oral contraceptive information. A questionnaire study of attitudes, knowledge and preferred information sources. JAMA 235:1331-1336, 1977.

5. Udkow GP, Lasagna L. Weintraub M. ct al: The safety and efficacy of the estrogen package insert. A questionnaire study. JAMA 242:536-539, 1979.

6. Morris LA, Olins NJ: Utility of drug leaflets for elderly consumer. Am J Public Health 74:157-158, 1984.

7. Sharpe TR. Mikeal RL: Patient compliance with antibiotic regimens. Am J Hosp Pharm 31:479-484. 1974.

8. Gotsch AR. Liguori S: Knowledge. attitude and compliance dimensions of antibiotic therapy with PPIs. Mcd Care 20:581-595, 1982.

9. Wiederholt JB, Kot7an JA: Effectiveness of the FDA designed patient package insert for benzodiazepines. Am J Ho.sp Pharm 40:828-834, 1983.

10. Miller HE: Patient education: Golden opportunity in health care field. Am Druggist 1982:24-26, 1982.

11. Sammons JH: Patien Me'dication Instruction Program. Chicago. American Medical Association, 1982.

12. Joubert P. Lasagna L: Patient Package inserts. Il. Toward a rational patient package insen. Clin Pharmacol Ther 18:663-669, 1975. 